\title{
Research on the Teaching Methods of Design Course Fused with Maker Concept
}

\author{
Haijiao Sun \\ Zhuhai College of Jilin University \\ Zhuhai, China 519041
}

\begin{abstract}
Art design is an extremely innovative professional. It is strongly practical, innovative and involves wide and closely relates to the production and living. Maker is a motivating creative activity. It pursues innovation and focuses on sharing. It takes advantages of tools and fuses playing with learning. They seem the same in terms of the characteristics, but the current teaching still adopts old methods, which is hard to motivate students. Therefore, the author tries to combine the maker concept with the courses teaching to research teaching methods based on the maker concept, makes maker fuse with class and teaching to make the students attend actively and experience fully in learning process and enjoy students with design courses.
\end{abstract}

Keywords-maker; maker concept; design course; teaching methods

\section{INTRODUCTION}

In today's internet economy booming era, "public entrepreneurship, public innovation" has become an important strategy to promote the development of China's economic in the future. Digital technology like Big data, cloud computing, MOOCs and Micro Course drives profound changes in the development of education and creativity, innovation and entrepreneurship education will become the breach of the education reform in colleges and universities. Enterprise's favored talents are professionals with abilities to apply major strength to business and innovation consciousness. Standards of innovative talents are the innovation idea, adventure spirit, strong executive ability and team spirit, which cannot be gained by traditional education methods. The core of maker concept is to cultivate talents with creative, innovative ability and creative thinking. Knowledge (technology) and business savvy as well as innovation talents represent the contemporary values and direction of the talent cultivation.

Maker stresses practical operation and research experience and the interaction feeling under the guiding ideology of learning in doing and creation. While design is not simple, it cannot be achieved by a design software or drawing. A design scheme often needs the support of multiple disciplines knowledge. Only applying a variety of knowledge and skills to design, constantly learning, constantly practice, constantly testing can we grasp the essence of design. Maker concept is in line with design on this point. What maker concept stresses is exactly what is ignored and should solve urgently in design education.
The combination of maker concept and design education has greatly influenced and changed traditional teaching methods, organization even education ideas. Design courses with maker concept regard "learning in creation" as the dominant idea to train innovative talents and study teaching methods. This mean provides new ideas for solving the current employment difficulty, students with high score low-energy and lack of innovative talents.

\section{CURRENT CONDITIONS AND THINKING ON TRADitional DESIGN TEACHING}

Traditional teaching mainly focuses on close teaching and much knowledge has little use in modern design activities in students' eyes. For example, the knowledge of "cold courses" like history class seems to be derailed with modern times. These traditionally narrative and spoon-feeding ways of teaching methods cannot satisfy students living in information age and network times. Data show that among 100 thousand phone users, there are more than half (mostly college students) who use their phone at least 3 hours a day. While the video, music and games are the most popular ways for entertainment and communication. This shows that fragmentation and datamation spread ways are the most suitable for the young. Then, how to make low viscous medium such as paper textbooks, PPT courseware and teacher-centered teaching methods more suitable for the young to learn and communicate? How to make them participate, learn and interactive actively? As a worker for design in higher education, we should adopt original teaching methods and way to motivate students. We should establish practical multi-track interacting teaching models to improve teaching datamation and interaction in order to appeal young people.

\section{BASIC IDEAS FOR INTRODUCING MAKER CONCEPT INTO CLASS}

\section{A. Building Maker Atmosphere}

To build maker atmosphere, we should build supporting environment. First, we should set real maker space in learning and life. It may be a studio or a lab and students can do what they are interested in there. Second, we should have relative virtual space, namely cyber space. This is used to display design works, communicate and share experience, make tools, software and materials and making process for students. 


\section{B. Setting Maker Course in Curriculum System}

Deeply analyzing the current cultivation scheme and the course, and then reforming the content of the course structure based on the maker concept can carry out and implement maker course better. In this process, first of all, we should pay attention to the integrity and continuity of subject content and pay attention to the contemporaneity of course materials to ensure that course content links to times closely. In addition, we should emphasis on the integration of curriculum and information technology, such as the introduction of a variety of technology tools, media, software, etc. What's more important is to value the practice of activities courses as much as possible, arouse the enthusiasm of learning to make students learn actively and consciously and be willing to share and exchange rather than the traditional education mode of the non-computer majors.

\section{Changing the Way of Learning}

The most distinctive characteristic of maker education different from traditional education is the transformation of learning ways. Teachers in design education should find the bonding point of maker education and subject teaching and try their best to fuse maker concept with design courses. Maker learning is the transformation of both teaching methods and learning ideas. Whatever can highlight active learning and practice is the suitable way for maker learning.

\section{Building Professional Teaching Groups}

Maker is a comprehensive and difficult activity. In the learning process, students need great professional knowledge and much other knowledge such as subject knowledge, relevant knowledge, tools and technologies as well as Creative inspiration. Only practical teachers with solid professional knowledge and comprehensive quality can give professional guidance to the students during this process. So it is necessary to build knowledgeable and skilled teaching groups with stronger sensitivity and ability to apply advanced technology.

\section{STEPS FOR THE REFORM OF DESIGN TEACHING}

\section{A. Making Training Goal Clear}

According the yearly design teaching experiences and employment, we should make the requirements on design talents clear under the information age and apply maker to student cultivation and cultivation scheme. We should break traditional education ideas and change cultivating patterns to cultivate students' maker spirit and improve their practical ability of enterprise and research the design course system restructure on this basic.

\section{B. Optimizing Design Courses}

In terms of professional ability, we should cultivate originality, aesthetics and skills of students. Originality ranks first in the innovative age while aesthetics and skills are important constitution. We should restructure and optimize traditional design courses in these respects. We should take maker concept as the guidance and cultivate students' aesthetics and skills at the same time.

\section{Setting Maker Space Related to Design Courses}

Building auxiliary system related to teaching in design courses. The contents include reference books, teaching materials, various teaching videos, excellent student works and good cases analysis. Building physical maker space (lab or studio) and the interaction of virtual community (cyber space) and class are to support class teaching and establish mutual and diversified auxiliary resources. For example, Our department has opened up a boutique resources sharing site, including making the sand table model and graphic originality design courses, such as detailed teaching videos of teachers, making videos of students in design laboratory, related advanced equipment and operating videos, introductions of materials and tools, display of design works and the interaction between teachers and students. The integration of physical maker space and virtual community has greatly improved the participation and interaction of students.

\section{Setting Expanding Courses for Design Courses}

Many maker activities need expanding knowledge beside professional knowledge. After guiding a number of practice activities for college students, we find the maker design needs assistance from expanding courses, a wide knowledge of humanities such as operation and management, policies and regulations, intellectual property.

\section{Teaching Methods Embodying MaKer ConcePt}

\section{A. Item Teaching Method}

Item teaching method for design courses can be a certain task given by teachers or a task that students interested in. The practice process can be several days or weeks according to the difficulty of tasks. It can be divided into final goal, phase goal and accomplishing means if without fixed outline. During the process, it stresses focusing on students to cultivate their selflearning ability. For example, opening innovative entrepreneurial project proposed by students themselves. Students can make interesting practical and professional projects according to their interests such as design for magnetic energy chair, innovative application of wash painting in garment materials, reuse of wasted materials in installation art, Junyi art culture creativity co., LTD, combination and application of wood elements and lamps and lanterns as well as research and development of art derivatives of museum. It is easy to see that these projects need diversified knowledge, while students still actively find related information and contents by kinds of media to complete them. In the process, members of each project complete their task in advance, and design together, communicate with each other and share with each other.

\section{B. Experienced Teaching}

Comparing to item teaching method, experienced teaching also center on students. Teachers act as assistants and guiders in this process to motivate students to attend and interact. For example, in the course of making sand table model, we show students the around model making company at first to experience the whole making prededure, then teach students sand table model making principle and steps as well as use of 
carved equipment carefully in the class. Finally, allow students to operate on $\mathrm{CNC}$ carved mechanism model to give experiences to students.

\section{DIY Teaching}

DIY teaching refers to introducing DIY into design teaching. It widely means carrying out design, make and modify in peoson. This concept is to encourage students to do it by yourself and enjoy the achievement. It can be said that DIY plays an important role in maker activities and many makers begin their maker career from DIY. Actually this method has applied in our comprehensive training courses already. For example, we require students to finish deisgning and making insects. We don't restrict the materials, methods and tools, as a result, works of studnets are various and interesting. Some are made in copper wire, some hardboard, some screws and nuts and some are made up of polymer clay. This method enables students to image and appeal them, which produces unexpected class effect.

\section{Innovating Education Courses}

Accomplishing overall goals of cultivating the students' creativity according to innovative technology, a new theory and new methods of a certain design category to increase practice innovation consciousness, innovation ability, innovative thinking and innovative means of students gradually in the process. In the implementation process, edcators can choose different forms according to the integrity and continuity of design course, such as using threedimensional photographic techniques and three-dimensional printing technology to produce product model.

\section{CONCLUSION}

There are two important subjects in design teaching methods with maker concept: One is to cultivate talents with maker spirit, the other is the teachers should uphold the maker spirit in teaching. The two are mutually fused and supported. The final goal is to cultivate innovative talents with innovation consciousness, innovation ability and innovative thinking.

Maker activity gives impetus to the reform of design education. The learning methods emphasias on "learning in creation" and the teaching methods to train various kinds of innovative talents are an extension of learining in doing, enjoying in learning. Maker education has great potential and will influence individual development, design courses reform and talents cultivation.

\section{REFERENCES}

[1] "Finding maker - New ecological education under the view of new industrial revolution" Wang Youmei, Open Education Research, Oct 5, 2015

[2] "Seeking the source of maker and its cultural history factors" Ding Daqin, Social Science of Beijing, Aug, 2015

[3] From interdisciplinary courses to cultivating open and innovative talents - written on the tenth anniversary of information design department, Academy of arts\&design, Tsinghua University, Fu Zhi yong, Decoration, Dec 1, 2014
[4] "A research on the art design talent in innovation and teaching practice under the new situation" Du Bing, Industrial design, Oct 20, 2014

[5] "Maker action in education" Erica Rosenfeld Halverson, Modern Distance Education Research, May 25, 2015 